\title{
Construction and function of a fusion protein consisting of a single-chain variable fragment and RBP4
}

\author{
HONGXIA LI ${ }^{1,2^{*}}$, GUANGMING CAO $^{1 *}$, TONG LOU $^{1}$, ZHENYU ZHANG $^{1}$ and CHONGDONG LIU ${ }^{1}$ \\ ${ }^{1}$ Department of Obstetrics and Gynecology, Beijing Chao-Yang Hospital, Capital Medical University, Beijing 100020; \\ ${ }^{2}$ Department of Obstetrics and Gynecology, Civil Aviation General Hospital, Beijing 100123, P.R. China
}

Received November 15, 2018; Accepted April 12, 2019

DOI: $10.3892 / \mathrm{mmr} .2019 .10270$

\begin{abstract}
Preeclampsia is one of the complications of pregnancy. Often presenting as new-onset hypertension and proteinuria after 20 weeks of gestation in a previously normotensive patient, it can progress rapidly to serious complications, and is a leading cause of maternal and perinatal mortality. The present study involved the construction of a fusion protein consisting of a single-chain antibody variable fragment ( $\mathrm{scFv}$ ) and the retinol-binding protein 4 (RBP4). and investigated the function of this protein. The MaxCodon ${ }^{\mathrm{TM}}$ Optimization Program (v13) was used to optimize the amino acid sequence of the scFv-RBP4 fusion protein and full-length splice primers were designed by Detai Bio Tech. The scFv-RBP4 gene was inserted into a proEM expression vector using double digestion, and the accuracy of the final expression vector was confirmed by restriction enzyme digestion and sequencing. The plasmid was transfected into DH5 $\alpha$ competent cells and the plasmid was extracted from cells using a transfection reagent. The plasmid and $\mathrm{scFv}-\mathrm{RBP} 4$ fusion protein were purified by nickel-iminodiacetic acid affinity chromatography. Cell proliferation was determined using the Cell Counting Kit- 8 assay and cell invasion was measured using a Transwell invasion assay. The results from the digestion and sequencing showed that the scFv-RBP4 fusion protein was constructed correctly and that the purity of the target protein was $>90 \%$. The scFv-RBP4 fusion protein was stably expressed in 293T cells. The scFv-RBP4 fusion protein was extracted from the 293T cells and functional studies were carried out. The
\end{abstract}

Correspondence to: Professor Zhenyu Zhang or Dr Chongdong Liu, Department of Obstetrics and Gynecology, Beijing Chao-Yang Hospital, Capital Medical University, 8 Gongti South Road, Chao-Yang, Beijing 100020, P.R. China

E-mail: zhang_zhenyu112@sina.com

E-mail: liu_dong12@sina.com

${ }^{*}$ Contributed equally

Key words: retinol-binding protein 4, fusion protein, single-chain antibody variable fragment, 293T cells, construction, function
scFv-RBP4 fusion protein significantly increased the invasion, but not the proliferation, of HTR8/SVneo cells.

\section{Introduction}

Preeclampsia (PE) is a pregnancy-related disorder, with symptoms including new-onset hypertension, proteinuria commonly occurring after 20 weeks of gestation. PE affects $3-8 \%$ of pregnancies worldwide (1) and is a major contributor to maternal and fetal morbidity and mortality (2). As methods to mitigate, prevent and treat $\mathrm{PE}$ are lacking, terminating the pregnancy and treating the symptoms have become effective approaches. Therefore, PE has become a primary cause of fetal mortality. Invasive villous trophoblastic cells invade the maternal endometrium and myometrium reshaping the uterine spiral artery. These cells ultimately provide effective and stable placental blood flow and play a vital role during the process of forming the placenta. Similar to tumor cells, invasiveness is a feature of trophoblasts; however, unlike tumor invasion, trophoblastic invasion is a tightly controlled physiological event $(2,3)$. Abnormalities in the differentiation of trophoblasts are associated with a variety of diseases during pregnancy. Insufficiencies in the invasion and proliferation of trophoblasts are known to be correlated with the development of PE (4,5). Human chorionic gonadotropin (hCG) is a glycoprotein hormone composed of $\alpha$ and $\beta$ subunits that is secreted by trophoblasts. hCG is necessary for the implantation of embryos and the maintenance of pregnancy. Retinol-binding protein 4 (RBP4) is secreted by the liver and adipose tissue, and was originally identified as a specific transporter of vitamin A (6). A number of studies have suggested that RBP4 is involved in the development of obesity and insulin resistance, as such RBP4 is considered to be a new adipose-derived factor $(7,8)$. A fusion protein involves merging two or more different protein domains into a single protein molecule using recombinant DNA technology. The goal of fusion protein technology is to achieve an increase in performance by combining the functions of the different proteins (9). In this present study, an anti-hCG antibody was used to target RBP4 to placental tissue by constructing an anti-hCG antibody: RBP4 [single-chain antibody variable fragment (scFv)-RBP4] fusion protein. This fusion protein could thus improve the local RBP4 concentration in the placenta and may lead to new strategies for the treatment of PE. 


\section{Materials and methods}

Construction and purification of the $s c F v-R B P 4$ fusion protein. The RBP4 and anti-hCG scFv sequences were obtained from the NCBI database (RBP4 chain pro0000017961). The amino acid sequence of the scFv-RB4 protein was optimized and a full-length splicing primer was designed by Detai Biotechnology. The template was optimized using MaxCodon Optimization Program (version 13) (Detai Biotechnology). The scFv-RBP4 gene was inserted into the expression vector proEM (Detai Biotechnology) by double enzyme (T4 DNA ligase, TaqDNA polymerase) digestion. The accuracy of the final expression vector was confirmed by restriction enzyme (EcoRI and BamHI; New England BioLabs, Inc.) digestion and sequencing. The final expression vector was transformed into DH5 $\alpha$ competent cells (Detai Biotechnology) and transfection grade plasmid was extracted using a plasmid purification kit (Qiagen $\mathrm{GmbH}$ ). Following extraction, the expression plasmids were analyzed by agarose gel electrophoresis using a $1 \%$ gel. The plasmid was transfected into the mammalian 293T cell line (Xi Bei Hong Cheng Biological Technology Co., Beijing, China) using Qiagen Plasmid Maxi kit (Qiagen $\mathrm{GmbH}$ ) for transient expression and the $\mathrm{scFv}$-RBP4 fusion protein was purified by nickel-iminodiacetic acid (Ni-IDA) affinity chromatography.

Cell culture. The immortalized human trophoblast cell line HTR8/SVneo was obtained from the American Type Culture Collection. Cells were cultured in RPMI-1640 medium (HyClone; GE Healthcare Life Sciences) supplemented with 10\% FBS (Gibco; Thermo Fisher Scientific, Inc.), $100 \mathrm{U} / \mathrm{ml}$ penicillin and $100 \mathrm{mg} / \mathrm{ml}$ streptomycin in a $37^{\circ} \mathrm{C}$ humidified incubator with $5 \% \mathrm{CO}_{2}$. The cells were sub-cultured at a ratio of 1:3 when the cultures reached $80-90 \%$ confluence.

The 293T cells were cultured in suspension 2 days before transfection. The inoculation density was $4-5 \times 10^{5}$ cells $/ \mathrm{ml}$. The cells were incubated in suspension after $4-6$ days at $37^{\circ} \mathrm{C}$ with $5 \% \mathrm{CO}_{2}$ at $110 \mathrm{xg}$.

Transfection of the scFv-RBP4 plasmid into $293 T$ cells. The extracted scFv-RBP4 plasmid was transfected into 1 liter of 293T cells using a transfection-grade plasmid extraction kit (Qiagen $\mathrm{GmbH}$ ) and the cells were incubated in suspension at $110 \mathrm{rpm}$ at $37^{\circ} \mathrm{C}$ in a $5 \% \mathrm{CO}_{2}$ incubator. The cell density was maintained at $1.5-2 \times 10^{6}$ cells $/ \mathrm{ml}$. For the transfection, the DNA (1,500 bp)-polyethylenimine (PEI) mixture was at a mass ratio of 1:5; the DNA was first added to the transfection buffer and was then added to the incubation buffer. Between 4 and 6 days after transfection at $37^{\circ} \mathrm{C}$ in a $5 \% \mathrm{CO}_{2}$ incubator the cell suspension was centrifuged at $800 \mathrm{xg}$ at $37^{\circ} \mathrm{C}$ for $6 \mathrm{~min}$ to collect the supernatant and cells.

Protein purification. The supernatant was filtered through a $0.22 \mu \mathrm{m}$ membrane and dialyzed in buffer $1(25 \mathrm{mM}$ Tris, $150 \mathrm{mM} \mathrm{NaCl}, \mathrm{pH} 8.0$ ) at $4^{\circ} \mathrm{C}$ for $30 \mathrm{~min}$. After dialysis, purification was performed using a Ni-IDA affinity chromatography column. The fusion protein was collected and dialysis repeated in buffer 2 (1X PBS, $10 \%$ glycerol, $\mathrm{pH}$ 7.4). After dialysis, the fusion protein was filtered through a $0.22 \mu \mathrm{m}$ membrane and stored at $-80^{\circ} \mathrm{C}$.
Freeze-thaw stability test. The scFv-RBP4 protein that had been frozen at $-80^{\circ} \mathrm{C}$ was placed in an ice-water mixture until the sample slowly thawed; no abnormality occurred after thawing. The scFv-RBP4 protein was subjected to western blot analysis verification after repeated freeze-thaw cycles and demonstrated no significant change in protein content, indicating that the scFv-RBP4 protein had normal characteristics.

Protein extraction. Total cellular proteins were extracted using RIPA $200 \mu 1$, Pi $22 \mu 1$ and PMSF $5 \mu 1$, (Abcam). Following centrifugation at $12,000 \mathrm{x}$ g at $4^{\circ} \mathrm{C}$ for $15 \mathrm{~min}$, the protein concentrations of the supernatants were determined using the Bradford assay. A set of BSA (Abcam) standards at $1.0,0.8,0.6,0.4$ and $0.2 \mathrm{mg} / \mathrm{ml}$ in PBS was used. Another $1 \mathrm{ml}$ of the PBS solution (BSA solution concentration of $0 \mathrm{mg} / \mathrm{ml}$ ) was used as a control. A volume of $50 \mu \mathrm{l}$ was removed from each BSA solution and was added to a 96-well plate. The same volume of the protein solutions to be tested was placed in the other wells of the plate and $200 \mu \mathrm{M}$ Coomassie Brilliant Blue was then added. After incubating the plate for 10 min at $37^{\circ} \mathrm{C}$, the optical density values of the BSA standards were measured at $595 \mathrm{~nm}$ using a microplate reader. A standard curve was generated and the protein concentrations were calculated.

SDS-PAGE and western blot analysis. Total cellular proteins were extracted (as detailed above). Following centrifugation at $12,000 \times \mathrm{g}$ and $4^{\circ} \mathrm{C}$ for $15 \mathrm{~min}$, the protein concentrations of the supernatants were determined using a Bradford assay. Equal amounts of the total proteins $(3 \mu \mathrm{g})$ were loaded per lane and separated via $10 \%$ SDS-PAGE. After electrophoresis, the gel was placed in a clean glass container, and 5 times the gel volume of Coomassie Brilliant Blue G-250 dye was added. The gel was incubated for $1 \mathrm{~h}$ at room temperature with agitation to disperse the large colloid particles of the added Coomassie Brilliant Blue G-250 dye. The liquid was then drained. After boiling and incubating overnight at room temperature, the gel was rinsed with water to observe the decolonization effect. After electrophoresis, the samples were transferred to nitrocellulose membranes using standard procedures. The primary antibody used was rabbit polyclonal anti-RBP4 (1:1,000; Abcam). Equal amounts of total protein $(3 \mu \mathrm{g})$ were probed with primary antibody in 5\% SBS (Abcam)/PBS-Tween-20 solution overnight at $4^{\circ} \mathrm{C}$. The membranes were rinsed several times with PBS-Tween-20 solution and then incubated with Goat anti-rabbit, HRT conjugated secondary antibody $(1: 3,000 ; a b 6721 ;$ Abcam) for $2 \mathrm{~h}$ at room temperature. Excess secondary antibody was removed by washing four times in PBS-Tween 20 solution. Bands were visualized and imaged using an ECL Western Blot kit (CW Biotech) and densitometry was performed using ImageJ software (version $1.49 \mathrm{e}$, National Institutes of Health).

Identification of fusion proteins by matrix assisted laser desorption/ionization time-of-flight (MALDI-TOF) mass spectrometry (MS). Positron flight mass spectrometry was used at $\mathrm{m} / \mathrm{z}$ of 1122.7. Protein bands on the SDS-PAGE gel were excised and subjected to MALDI-TOF-TOF MS/MS protein profiling using an ABI 4700 mass spectrometer (Applied Biosystems; Thermo Fisher Scientific, Inc.). 
Table I. Construction and purification of the scFv-RBP4 fusion protein.

\begin{tabular}{cl} 
Chain & \multicolumn{1}{c}{ Protein sequence } \\
\hline VL & $\begin{array}{l}\text { DIVMSQSPSS LAVSVGEKVT MTCKSSQSLL YSSNQMNYLA WYQQKPGQSP KLLIYWASTRESGVPDRFTG } \\
\text { SGSGTDFTLT ISSVEAEDLA VYYCQQYHSY PFTFGSGTKL EIKRAGGGGSG }\end{array}$ \\
VH & GGGGSGGGGSEVNLEESGGG LVQPGGSMKL SCVASGFTFS NYWMNWVRQS PEKGLEWVADIRLKSNNYA \\
& TLYAESVKGR FTISRDDSKS SVYLQMNNL RAEDTGIYYC TRGAYYRYDY AMDYWGQGTS VTVSS \\
RBP4 & GGSGGGGSER DCRVSSFRVK ENFDKARFSGTWYAMAKKDPEGLFLQDNIVAEFSVDETGQMSATAKGRVR \\
& LLNNWDVCAD MVGTFTDTED PAKFKMKYWG VASFLQKGND DHWIVDTDYD TYAVQYSCRL \\
& LNLDGTCADS YSFVFSRDPN GLPPEAQKIV RQRQEELCLA RQYRLIVHNG YCDGRSERNLL
\end{tabular}

The last residues of scFv were GGGGSGGGGSGGGGS. The first residues of the RBP4 protein were GGGSGGGGS.

Cell treatment. HTR8/SVneo cells were seeded, at a density of 5,000 cells per well, into a 96-well plate with different concentrations of scFv-RBP4 $(0,1,10,100 \mu \mathrm{g} / \mathrm{ml}), \mathrm{RBP} 4$ $(0,1,10,100 \mu \mathrm{g} / \mathrm{ml})$ and anti-hCG $(0,1,10,100 \mu \mathrm{g} / \mathrm{ml})$ along with control HTR8/SVneo cells. The Cell Counting Kit-8 (Sigma-Aldrich; Merck KGaA) was used to assay cell survival at $0,24,48$ and $72 \mathrm{~h}$. The optical density was measured at $450 \mathrm{~nm}$. These experiments were performed three times.

Transwell invasion assay. Cell invasion was assessed using Transwell chambers (24-well inserts; $8 \mu \mathrm{m}$-pore size) that had been precoated with Matrigel $(200 \mu \mathrm{g} / \mathrm{ml}$; BD Biosciences). Briefly, 24 h after transfection, HTR8-SVneo cells were trypsinized and seeded into the upper chambers $\left(5 \times 10^{5}\right.$ cells/chamber $)$ in serum-free medium. Different concentrations of scFv-RBP4 $(0,1,10,100 \mu \mathrm{g} / \mathrm{ml}), \mathrm{RBP} 4(0,1,10,100 \mu \mathrm{g} / \mathrm{ml})$ and anti-hCG $(0,1,10,100 \mu \mathrm{g} / \mathrm{ml})$ were used. The lower chambers were filled with RPMI-1640 medium containing $10 \%$ FBS as a chemoattractant. The plates were incubated for $48 \mathrm{~h}$, at which point the cells on the upper surface of the chambers were gently removed. The cells that had invaded to the surface of the lower chambers were fixed in paraformaldehyde (4\%) at room temperature for $20 \mathrm{~min}$ and stained with crystal violet $(0.1 \% \mathrm{~g} / \mathrm{ml})$ at room temperature for $30 \mathrm{~min}$; the number of cells in four randomly selected fields of view were imaged using a light microscope (magnification, $\mathrm{x} 10$ ) and were counted.

Statistical analysis. Statistical analysis was performed using SPSS 20.0 software (IBM Corp.). Normally distributed data were described as the mean \pm standard deviation, and non-normally distributed data were described as the median (interquartile range). The data were tested $>3$ times for normality using a Shapiro-Wilk test and analyzed using t-tests, one-way ANOVA, a multiple comparison post hoc test (least significant difference) and nonparametric tests (Mood's median test). $\mathrm{P}<0.05$ was considered to indicate a statistically significant difference.

\section{Results}

Construction and purification of the scFv-RBP4 fusion protein. The full-length RBP4 fusion protein is 453 amino acids. The target sequence is variable light chain + variable heavy chain + RBP4 . The scFv-RBP4 protein length $=453$;

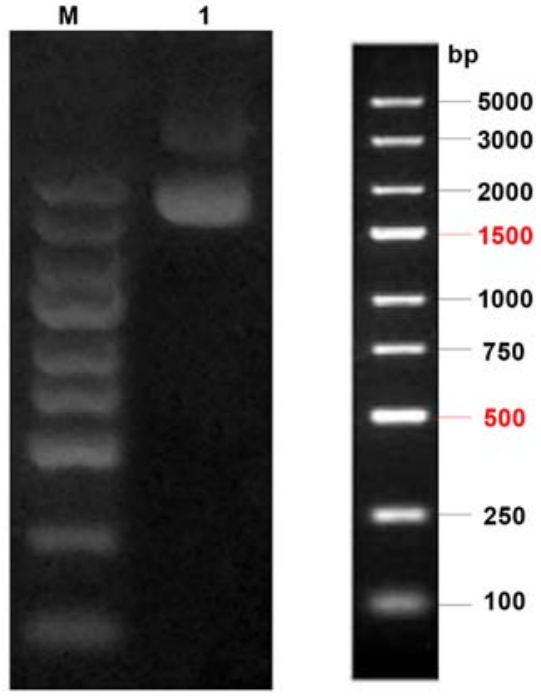

Figure 1. Analysis of the extracted scFv-RBP4 plasmid by agarose gel electrophoresis. Lane M, DNA markers; lane 1, scFv-RBP4 plasmid.

molecular weight $=50,242.7 \mathrm{kDa}$. The last residues of $\mathrm{scFv}$ were GGGGSGGGGSGGGGS. The first residues of the RBP4 protein were GGGSGGGGS (Table I).

Verification of the transfection plasmid. The expression plasmid was digested and separated on a $1 \%$ agarose gel. The electrophoresis result showed that the final location on the gel strip was as predicted, as shown in Fig. 1.

$s c F v-R B P 4$ protein purification. The scFv-RBP4 protein was primarily present in the fraction eluted with $300 \mathrm{mM}$ imidazole (Fig. 2; lanes 5-7). The desired band was between the 40 and $60 \mathrm{kDa}$ protein markers and had a molecular weight of approximately $50 \mathrm{kDa}$.

Concentration of $s c F v-R B P 4$. Based on the Bradford method of protein concentration determination and using BSA as a standard, the final concentration of the scFv-RBP4 fusion protein was $1.04 \mathrm{mg} / \mathrm{ml}$, and the purity of the protein was $>90 \%$.

Identification of fusion proteins using MALDI-TOF. The protein bands corresponding to the predicted size of scFv-RBP4 on the SDS-PAGE gel (Fig. 3) were excised and 


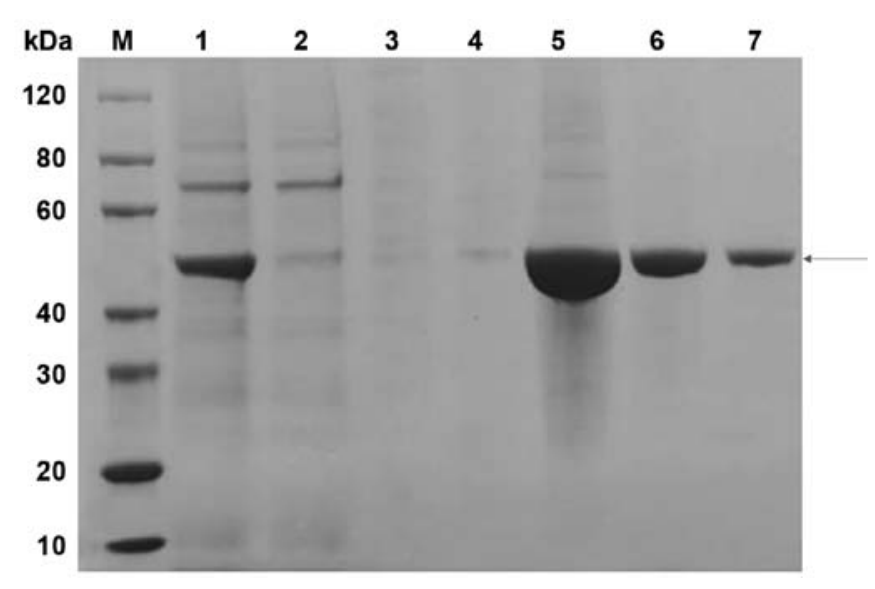

Figure 2. Visualization of scFv-RBP4 fusion protein purification by SDS-PAGE. Lane M, SDS-PAGE protein markers; lane 1, after centrifugation; lane 2, supernatant following nickel-iminodiacetic acid affinity chromatography; lanes 3-4, $30 \mathrm{mM}$ imidazole; lanes 5-7, $300 \mathrm{mM}$ imidazole.

subjected to MALDI-TOF-TOF MS/MS protein profiling using an ABI 4700 mass spectrometer. The resulting sequence was consistent with the theoretical sequence of scFv-RBP4 (Fig. 4) [protein score $=417$; protein score confidence interval $(\%)=100]$.

Verification of expression of $s c F v-R B P 4$ in trophoblast cells with different concentrations of RBP4 by western blot analysis. HBR8/SVneo cells were transfected with different concentrations of scFv-RBP4 fusion protein. The expression of the fusion protein was determined by western bolt analysis. The results showed that the expression of RBP4 was higher when a greater amount of plasmid was transfected into the cells (Fig. 5).

$s c F v-R B P 4$ does not increase the proliferation of HTR8/SVneo cells in vitro. The effect of scFv-RBP4 expression on the biological behaviors of trophoblast cells was investigated. scFv-RBP4 did not increase the proliferation of HTR8/SVneo cells (Fig. 6).

Invasive ability of HTR8/SVneo cells. Cell invasion assays were employed to investigate the effect of scFv-RBP4 expression on the invasive ability of HTR8/SVneo cells (Fig. 7). The results showed that expression of $\mathrm{scFv}$-RBP4 increased the invasive ability of HTR8/SVneo cells. With a higher expression of scFv-RBP4 the invasive ability of HTR8/SVneo cells was increased. The invasiveness of HTR8/SVneo cells did not change significantly in the hCG group; however, the invasive ability of the cells was increased with the expression of RBP4 protein alone (10 and $100 \mu \mathrm{g} / \mathrm{l})$.

\section{Discussion}

$\mathrm{PE}$ is a pregnancy-related disorder. The pathogenesis of PE is associated with a variety of factors (2). Unfortunately, the pathophysiology of this multisystemic disorder, which is characterized by an abnormal vascular response to placentation, remains unclear. The placenta is believed to be the primary cause of the disorder (10). During normal pregnancy, in the early stages of placental development, extravillous

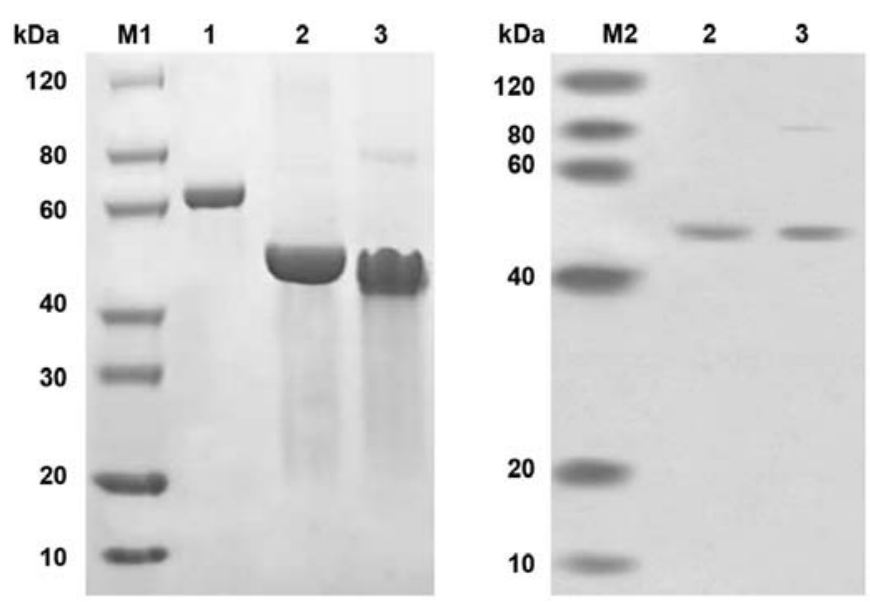

Figure 3. Expression of scFv-RBP4 protein. Lane 1, BSA (1.0 $\mu \mathrm{g})$; lane 2, scFv-RBP4 protein $(3.0 \mu \mathrm{g})$ (reduced); lane $3, \mathrm{scFv}-\mathrm{RBP} 4$ protein $(3.0 \mu \mathrm{g})$ (non-reduced); M1, SDS-PAGE markers; M2, western blot markers with the anti-His tag antibody.

cytotrophoblasts of fetal origin invade the uterine spiral arteries of the decidua and myometrium. The spiral arteries lose their endothelium and most of their muscle fibers, transforming these arteries from small, high-resistance vessels to high-caliber capacitance vessels capable of providing adequate placental perfusion to sustain the growing fetus. The invasive cytotrophoblasts replace the endothelial layer of the maternal spiral arteries. In PE, this transformation is incomplete, with almost no intravascular extravillous cytotrophoblastic invasion $(11,12)$. Therefore, the invasive capability of trophoblasts is an important factor in the occurrence of PE.

The development of during pregnancy PE can be life-threatening for the mother and the unborn child, leading to an increase in morbidity and mortality for both (13). In the case of the mother, PE may cause cardiovascular disease, including chronic hypertension, ischemic heart disease and stroke, later in life (14). For the child, preeclamptic pregnancies can lead to an increased risk of stroke, coronary heart disease and metabolic syndrome in adulthood (15). To date, delivery is the only curative treatment for PE (13).

The criteria that define $\mathrm{PE}$ have changed little over the past decade. The criteria include the following: Onset at $>20$ weeks of gestation; $24 \mathrm{~h}$ proteinuria $\geq 300 \mathrm{mg} /$ day or, if not available, a protein concentration $\geq 30 \mathrm{mg}$ ( $\geq 1$ on dipstick) with a minimum of two random urine samples collected at least 4-6 h, but no more than 7 days, apart; a systolic blood pressure $>140 \mathrm{~mm}$ $\mathrm{Hg}$ or a diastolic blood pressure $\geq 90 \mathrm{~mm} \mathrm{Hg}$ measured twice at least 4-6 h, but less than 7 days, apart using an appropriate cuff; and the disappearance of all these abnormalities before the end of the 6th postpartum week (16).

A single-chain antibody (single-chain fragment, $\mathrm{scFv}$ ) is a protein obtained via genetic engineering using a peptide linker sequence to combine the heavy-chain and light-chain variable regions of an immunoglobulin, thereby producing a single recombinant protein that has a complete antigen binding site. These small, genetically engineered antibody fragments, which are less immunogenic, can be expressed in bacteria and can be genetically engineered to construct fusion proteins linked to other effector molecules. There has been extensive application of scFv molecules in the penetration of tumor tissues (17). 


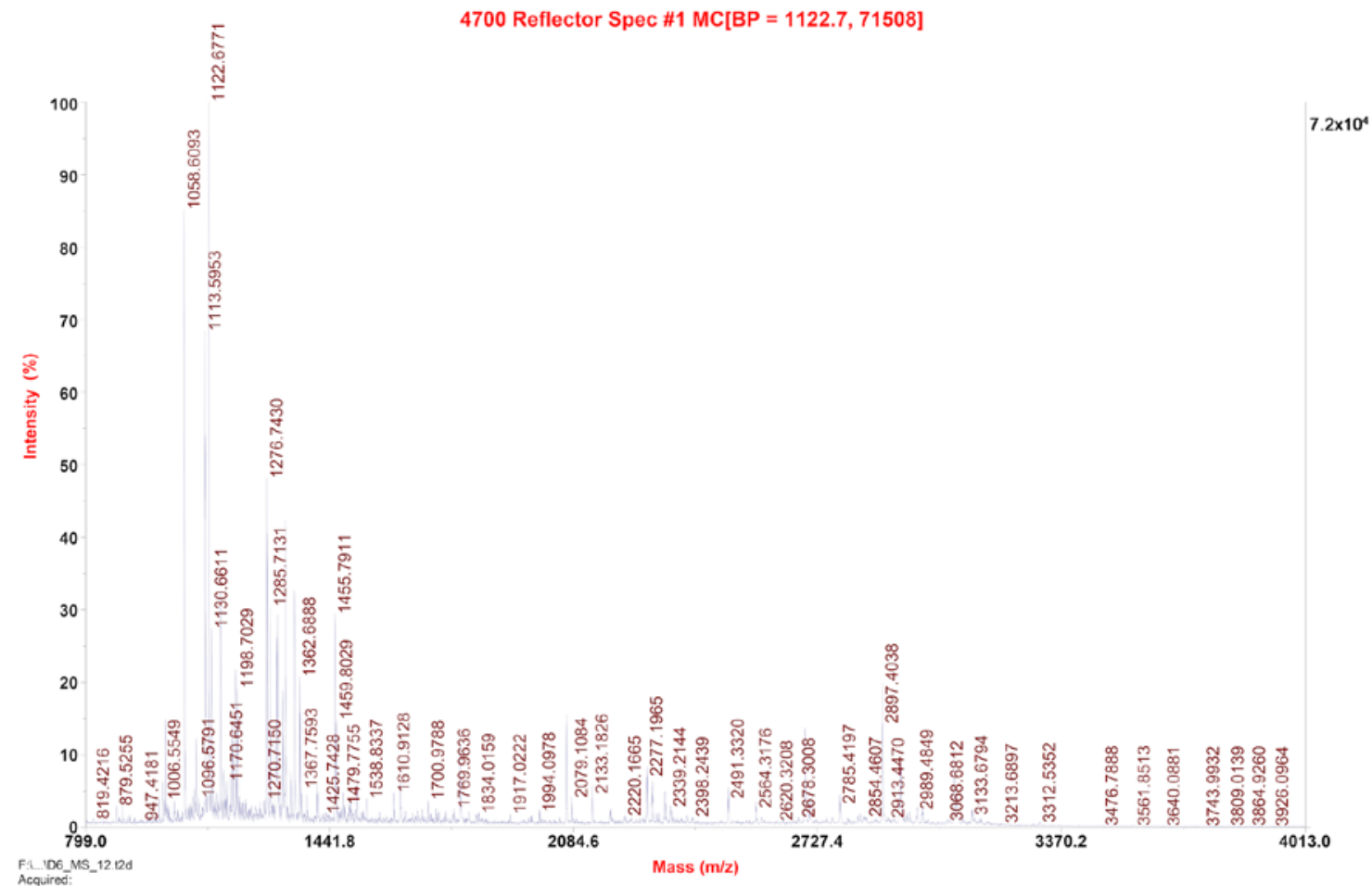

Figure 4. Identification of fusion proteins by MALDI-TOF. The protein bands corresponding to the predicted size of scFv-RBP4 on the SDS-PAGE gel were excised and subjected to MALDI-TOF-TOF MS/MS protein profiling using an ABI 4700 mass spectrometer. The sequence is consistent with the theoretical sequence (protein score $=417$, protein score confidence interval \%=100). MALDI-TOF, matrix assisted laser desorption/ionization time-of-flight; MS, mass spectrometry.
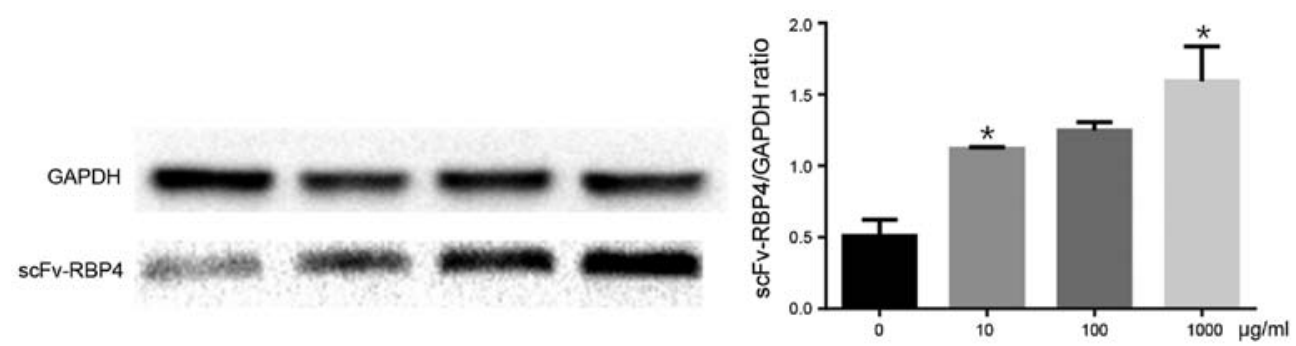

Figure 5. Expression of scFv-RBP4 fusion protein in HBR8/SVneo cells using western blotting. HBR8/SVneo cells were transfected with different amounts of scFv-RBP4 fusion protein and the expression of the fusion protein determined by western blot analysis. ${ }^{*} \mathrm{P}<0.05 \mathrm{vs} .0 \mu \mathrm{g} / \mathrm{ml}$.

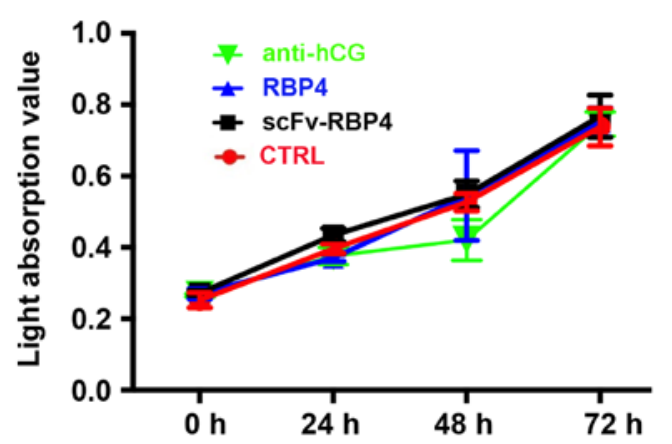

Figure 6. Expression of ScFv-RBP4 fusion protein, RBP4 or anti-hCG does not affect the proliferation of HTR8/SVneo cells. Cells numbers were counted at $0,24,48$ and $72 \mathrm{~h}$ after transfection using the Cell Counting Kit- 8 assay; the absorbance of the viable cells was determined at $450 \mathrm{~nm}$. The black line represents the HTR8/SVneo cells expressing scFv-RBP4 $(10 \mu \mathrm{g} / \mathrm{ml})$. The blue line represents the HTR8/SVneo cells expressing RBP4 $(10 \mu \mathrm{g} / \mathrm{ml})$. The green line represents the HTR8/SVneo cells expressing anti-hCG $(10 \mu \mathrm{g} / \mathrm{ml})$. The red line represents control cells. The data are presented as the mean \pm SD of three independent experiments. RBP4, retinol-binding protein 4; $\mathrm{hCG}$, human chorionic gonadotropin; CTRL, control.
RBP4, previously believed to only be a specific carrier for vitamin A and primarily produced by the liver (6), has recently been added to the rapidly expanding family of adipocyte factors (18). RBP4 is widely distributed in human blood, cerebrospinal fluid, urine and other bodily fluids. Chen et al (19) showed that RBP4 is not only a carrier of retinol but is also a circulating cytokine. Yang et al (18) reported that RBP4 is an adipocyte-derived signal that may contribute to the pathogenesis of type 2 diabetes. Lowering RBP4 may be a new strategy for treating type 2 diabetes. A previous study found that the concentration of RBP4 was significantly lower in women with severe PE than in women with a healthy pregnancy (20).

At present, the most important clinical application of $\mathrm{scFv}$ fusion proteins is in immune targeting. An scFv antibody fragment has reduced non-specific binding, allowing a greater concentration of $\mathrm{scFv}$ to reach a tumor and other regions. Because an scFv antibody fragment is regarded as the ideal carrier for target-guided drugs, these constructs have been widely used to treat tumor cells, thrombolysis and other 

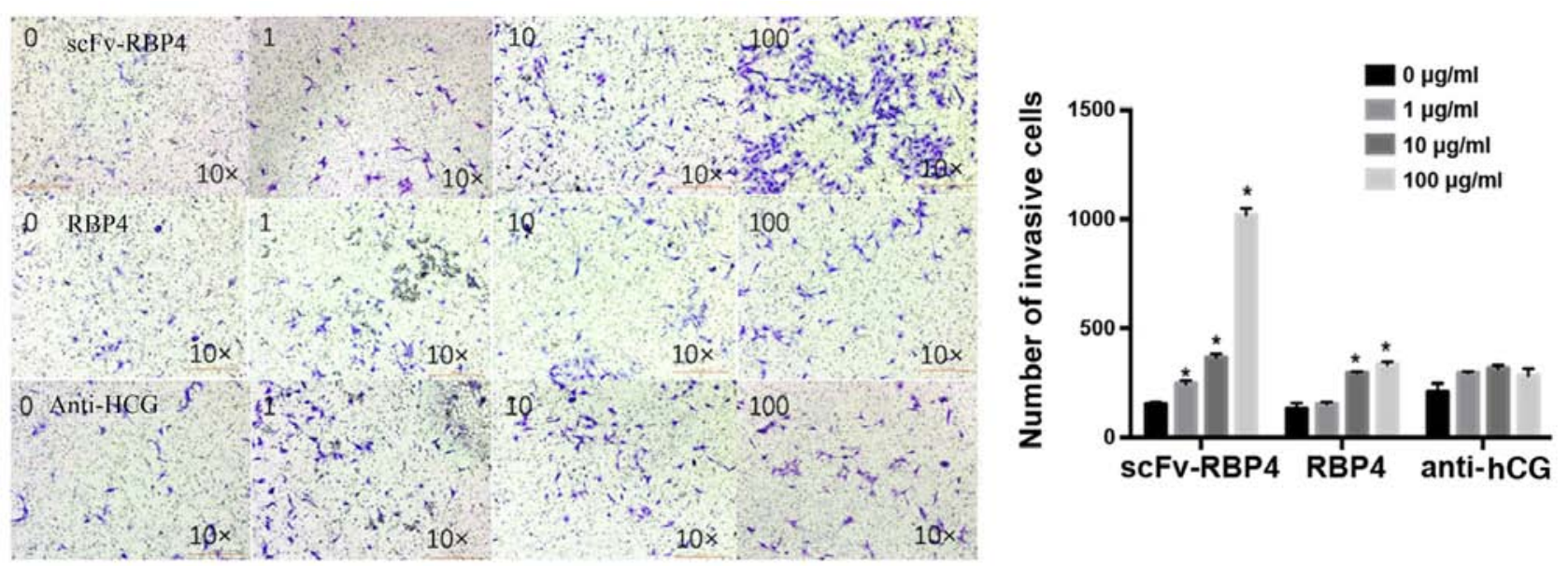

Figure 7. In an in vitro invasion assay HTR8-SVneo cells expressing different amounts of the scFv-RBP4 fusion protein, RBP4 or anti-hCG were analyzed for their invasive ability. Data are presented as the mean $\pm \mathrm{SD}$ of three independent experiments. ${ }^{*} \mathrm{P}<0.05$ vs. respective control. The results showed that expression of scFv-RBP4 increased the invasive ability of HTR8/SVneo cells. With a higher expression of scFv-RBP4 the invasive ability of HTR8/SVneo cells was increased. The invasiveness of HTR8/SVneo cells did not change significantly in the hCG group; however, the invasive ability of the cells was increased with the expression of RBP4 protein alone (10 and $100 \mu \mathrm{g} / \mathrm{l})$.

clinical diseases. The role of RBP4 in the pathogenesis of PE, improvements in trophoblastic infiltration and the shallow placental bed have rarely been reported. In this present study, an anti-hCG scFv-RBP4 fusion protein was constructed in vitro. The fusion protein components were independent of each other. RBP4 function was not affected by the scFv domain of anti-hCG, which can be used to target placental tissue and improve the local concentration of RBP4 at the placenta.

In conclusion, this present study showed that the scFv-RBP4 fusion protein was involved in the invasiveness of trophoblastic cells. scFv-RBP4 and RBP4 increased the invasive ability of HTR8/SVneo trophoblastic cells. Although the invasion produced by scFv-RBP4 expression may be significant, anti-hCG did not change the properties of trophoblasts. Decreased expression levels of RBP4 in the placenta may contribute to the development of $\mathrm{PE}$ by reducing the invasive ability of trophoblasts. These data suggest that the scFv-RBP4 fusion protein promotes the invasiveness of trophoblasts.

The advantages of fusion protein technology have not yet been demonstrated in the field of obstetrics. Therefore, further studies using this approach are required for the development of treatment strategies for PE.

\section{Acknowledgements}

Not applicable.

\section{Funding}

This work was supported by grants from the National Natural Science Foundation of China (grant no. 81571455) and by the Sino-RUS Cooperation Funds (grant no. 2015DFR31070).

\section{Availability of data and materials}

The datasets used and/or analyzed during the current study are available from the corresponding author on reasonable request.

\section{Authors' contributions}

All authors made substantial contributions to study conception and design, and the acquisition or analysis and interpretation of data. All authors were involved in drafting the manuscript or revising it critically for important intellectual content. All authors have given final approval of the version to be published. All authors have agreed to be accountable for all aspects of the work in ensuring that questions related to the accuracy or integrity of any part of the work are appropriately investigated and resolved. ZZ and CL conceived and designed the experiments. $\mathrm{HL}$ and TL performed the experiments. ZZ and GC analyzed the data. ZZ and CL interpreted the data and HL wrote the first draft of the manuscript. HL developed the structure and arguments for the paper. HL, CL and ZZ made critical revisions. All authors have reviewed and approved the final manuscript.

\section{Ethics approval and consent to participate}

The research protocol was conducted in accordance with the guidelines of the World Medical Association's Declaration of Helsinki and was performed following approval from the Medical Ethics Committee (11-S-59) of Beijing Chao-Yang Hospital, Capital Medical University.

\section{Patient consent for publication}

All patients enrolled in the study provided written informed consent before inclusion in the study.

\section{Competing interests}

The authors declare that they have no competing interests.

\section{References}

1. Poon LC and Nicolaides KH: Early prediction of preeclampsia. Obstet Gynecol Int 2014: 297397, 2014. 
2. Redman CW and Sargent IL: Latest advances in understanding preeclampsia. Science 308: 1592-1594, 2005.

3. Rana S, Lemoine E, Granger J and Karumanchi SA: Preeclampsia. Circ Res 124: 1094-1112, 2019.

4. Ball E, Bulmer JN, Ayis S, Lyall F and Robson SC: Late sporadic miscarriage is associated with abnormalities in spiral artery transformation and trophoblast invasion. J Pathol 208: 535-542, 2006.

5. Goldman-Wohl D and Yagel S: Regulation of trophoblast invasion: From normal implantation to pre-eclampsia. Mol Cell Endocrinol 187: 233-238, 2002.

6. Zanotti G and Berni R: Plasma retinol-binding protein: Structure and interactions with retinol, retinoids, and transthyretin. Vitam Horm 69: 271-295, 2004

7. Christou GA, Tselepis AD and Kiortsis DN: The metabolic role of retinol binding protein 4: An update. Horm Metab Res 44: 6-14, 2012.

8. Kotnik P, Fischer-Posovszky P and Wabitsch M: RBP4: A controversial adipokine. Eur J Endocrinol 165: 703-711, 2011.

9. Grönwall C and Ståhl S: Engineered affinity proteins-generation and applications. J Biotechnol 140: 254-269, 2009.

10. Uzan J, Carbonnel M, Piconne O, Asmar R and Ayoubi JM Pre-eclampsia: Pathophysiology, diagnosis, and management. Vasc Health Risk Manag 7: 467-474, 2011.

11. North RA, Ferrier C, Long D, Townend K and Kincaid-Smith P: Uterine artery Doppler flow velocity waveforms in the second trimester for the prediction of preeclampsia and fetal growth retardation. Obstet Gynecol 83: 378-386, 1994.

12. Meekins JW, Pijnenborg R, Hanssens M, McFadyen IR and van Asshe A: A study of placental bed spiral arteries and trophoblast invasion in normal and severe pre-eclamptic pregnancies. Br J Obstet Gynaecol 101: 669-674, 1994.

13. Sibai B, Dekker G and Kupferminc M: Pre-eclampsia. Lancet 365: 785-799, 2005.
14. Wang A, Rana S and Karumanchi SA: Preeclampsia: The role of angiogenic factors in its pathogenesis. Physiology (Bethesda) 24: 147-158, 2009.

15. Meads CA, Cnossen JS, Meher S, Juarez-Garcia A, ter Riet G, Duley L, Roberts TE, Mol BW van der Post JA, Leeflang MM, et al: Methods of prediction and prevention of pre-eclampsia: Systematic reviews of accuracy and effectiveness literature with economic modelling. Health Technol Assess 12: iii-iv, 1-270, 2008

16. Schroeder BM; American College of Obstetricians and Gynecologists: ACOG practice bulletin on diagnosing and managing preeclampsia and eclampsia. American College of Obstetricians and Gynecologists. Am Fam Physician 66: 330-331, 2002

17. Laginha KM, Moase EH, Yu N, Huang A and Allen TM: Bioavailability and therapeutic efficacy of HER2 scFv-targeted liposomal doxorubicin in a murine model of HER2-overexpressing breast cancer. J Drug Target 16: 605-610, 2008.

18. Yang Q, Graham TE, Mody N, Preitner F, Peroni OD, Zabolotny JM, Kotani K, Quadro L and Kahn BB: Serum retinol binding protein 4 contributes to insulin resistance in obesity and type 2 diabetes. Nature 436: 356-362, 2005.

19. Chen $\mathrm{CH}$, Hsieh TJ, Lin KD, Lin HY, Lee MY, Hung WW, Hsiao PJ and Shin SJ: Increased unbound retinol-binding protein 4 concentration induces apoptosis through receptor-mediated signaling. J Biol Chem 287: 9694-9707, 2012.

20. Lu Q, Liu C, Liu Y, Zhang N, Deng H and Zhang Z: Serum markers of pre-eclampsia identified on proteomics. J Obstet Gynaecol Res 42: 1111-1118, 2016.

This work is licensed under a Creative Commons Attribution-NonCommercial-NoDerivatives 4.0 International (CC BY-NC-ND 4.0) License. 